\title{
Apical barrier technique using MTA: report of two cases
}

\author{
A Sharma, Krishna, M Hans, S Shetty, S Dahiya \\ I.T.S. Dental College and Hospital, Greater Noida, U.P
}

\begin{abstract}
Open apices of pulpless immature teeth have always posed a problem as they need to be sealed before they are obturated. In recent years MTA has gained popularity as it provides a single step apical plug and thus helps in apexification. This article reports two cases which were successfully treated with MTA which had open apices.
\end{abstract}

Keywords: MTA, apexification, apical barrier

\section{Introduction}

Excellent apical seal in root canal treatment of tooth with open apices is one of the major technical problems. Obturation becomes difficult when the apex is open, for these types of cases apexification has become a paradigm. Apexification is a process in which root canal apex is closed artificially by a biocompatible material. It is done either retrograde or by orthograde method.

Calcium hydroxide and several other materials have been used to craft a hard tissue formation or an apical plug to prevent over filling of obturating material. Treatment of teeth with wide open apices generally take long period of time, and the prognosis is always poor. (2)

Many other materials like amalgam, EBA, Super EBS and Mineral trioxide aggregate (MTA) has been indicated as root end filling material. Several studies have reported its excellent biocompatibility, first-rate sealing ability and mechanical properties as apical sealing material. $(3,4)$ One of its major advantages is its fast setting time, which makes the process as a single step technique.

These cases describes the treatment of

1) Immature, non vital maxillary left central incisor

2) External apical resorption of right central incisor.

Address for correspondence

Dr. Abhinav Sharma

Sr. lecturer

I.T.S. Dental College and Hospital, Greater Noida, U.P.

Email address: drabhinavendo@gmail.com

\section{Case reports}

Case 1

A 15 year old boy who had met with trauma about six years ago, before he visited our department in ITS Dental College And Hospital, Greater Noida (UP) for the treatment of maxillary left central incisor.

Patient had met with trauma and no treatment had been performed until the moment. He had chief complaint of pain which was mild, intermittent and had started few days back.

Clinical examination revealed discoloration and mobility (grade 1). Radiolucency with context to 9 and open apex was evident, on radiographic evaluation. On the basis of clinical and radiographical examination, the case was diagnosed as chronic periapical abscess.

On the first appointment, rubber dam isolation was done and access opening was performed. Root canal instrumentation was performed using a conventional technique. Working length was established $1 \mathrm{~mm}$ short of the radiographic apex.

Copious irrigation was done using $3 \%$ sodium hypochlorite and $2 \%$ chlorhexidine through out the biomechanical preparation. The canal was dressed with intra canal medicament, calcium hydroxide and iodoform(metapex) and the access cavity was sealed with fast setting zinc oxide eugenol cement(IRM). Patient was then recalled after 15 days.

On second appointment, metapex was removed using $\mathrm{H}$ - files and MTA powder (Dental Tulsa Dentsply, De Tray, Germany) and distilled water 
were mixed and placed in the canal with the help of messing gun till a barrier of $4 \mathrm{~mm}$ was achieved. MTA was condensed with the help of pluggers which snugly fitted to the desired length.

After placement of MTA, most cotton was placed in the canal and then sealed with IRM.

Two days later patient was recalled and temporary filling was removed to check the hardness of MTA. Obturation was done using lateral condensation technique and permanent restoration was done. PFM crown was given after a month of obturation.

Size of the periapical lesion decreased significantly after one year of follow up.

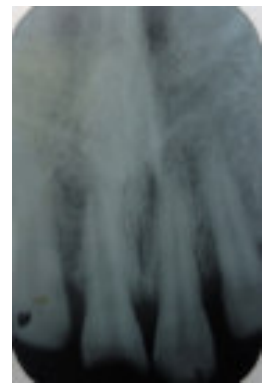

PREOPERATIVE RADIOGRAPH

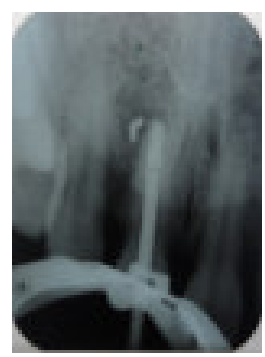

AFTER 1 YEAR

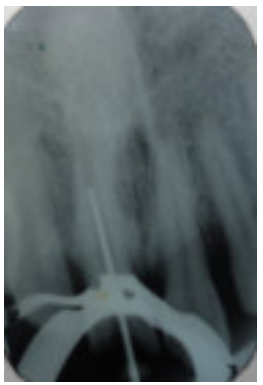

WORKING LENGTH DETERMINATION

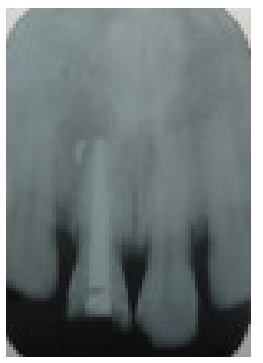

POST OBTURATION RADIOGRAPH

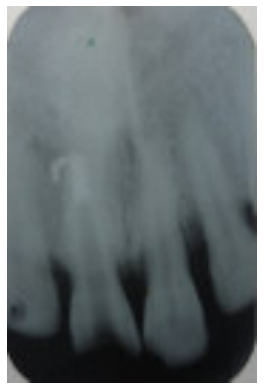

MTA RADIOGRAPH

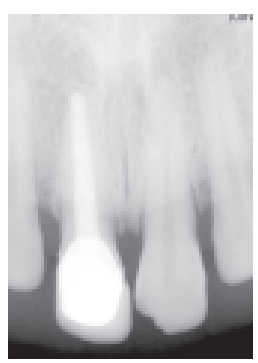

MASTER APICAL CONE RADIOGRAPH

\section{Case 2}

A 24 year old male patient, visited our department ITS Dental College And Hospital, Greater Noida (UP) for the treatment of maxillary right central incisor.

He had chief complaint of pain which was mild and intermittent.

Clinical examination revealed fractured central incisor, ie 8 (Ellis class IV fracture). Sinus was also present in relation to the upper right central incisor. Radiolucency with context to upper right central incisor and open apex was evident with tooth no. 8, on radiographic evaluation. Keeping all the points in mind, it was diagnosed as chronic periapical abscess.
Resorption was also evident at the apex with blunt and wide open apex.

Access opening was performed after rubber dam isolation. Working length was established $1 \mathrm{~mm}$ short of the radiographic apex, which was $22 \mathrm{~mm}$.

Root canal instrumentation was performed using a conventional technique and circumferential filling in 8. Copious irrigation was performed using $3 \%$ sodium hypochlorite and $2 \%$ chlorhexidine through out the biomechanical preparation. The canal was dressed with intra canal medicament, calcium hydroxide and iodoform (metapex) and the access cavity was sealed with fast setting cavit.

Patient was recalled after two weeks.

Intracanal medicament ie. Metapex was removed using $\mathrm{H}$ - files and root canal was irrigated. After drying the canal with sterile paper points, MTA ( Dental Tulsa Dentsply, De Tray, Germany) was then applied in the canal till a barrier of $4 \mathrm{~mm}$ was achieved. MTA was condensed with the help of pluggers which snugly fitted to the desired length. Moist cotton was inserted into the canal and was sealed with cavit.

A day later patient was recalled and temporary filling was removed to check the hardness of MTA. Obturation was done on the same day using lateral condensation technique and permanent restoration was done.

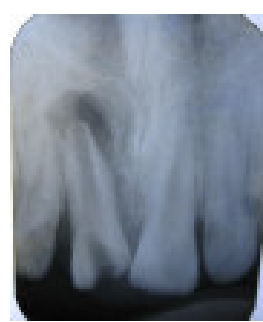

WORKING LENGTH DETERMINATION

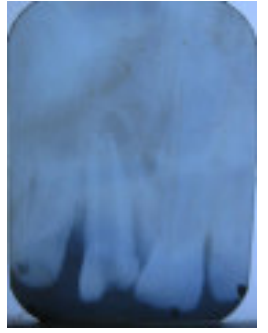

POST

OBTURATION RADIOGRAPH

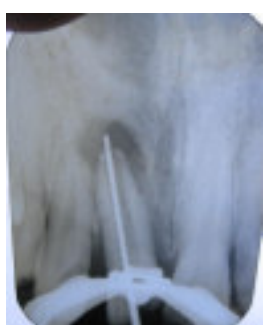

METAPEX RADIOGRAPH

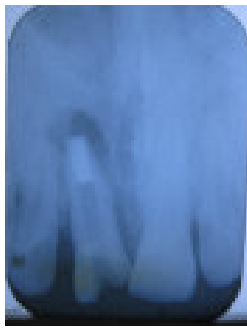

RADIOGRAPH AFTER PLACING MTA

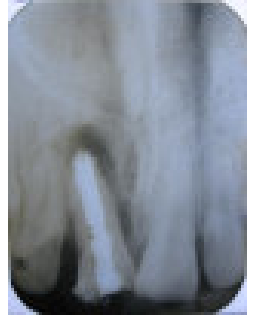

PREOPERATIVE RADIOGRAPH

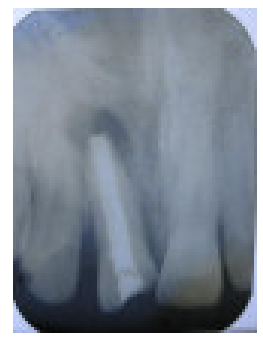

METAPEX

REMOVED AFTER 15 DAYS 


\section{Discussion}

It is essential to choose a treatment plan that is best for patient and dentist in complicated cases. Apexification is a method by which artificial barrier in the root apex is formed in such a way that obturating material can be filled in the canal space. Calcium hydroxide has been extensively used to accomplish apical closure due to its ability to induce hard tissue formation, but it is more time consuming. $(4,5)$. MTA was used in immature premolars of dogs and was concluded that it induced apical plug more often with less inflammation.(6) MTA has shown good sealing abilities and biocompatibility to the periradicular tissue. $(7,8,9)$ MTA has been successfully used as an apical barrier. $(10,11)$ In this case maintaining sterilization of root canal, intracanal medicament, good apical seal using MTA and a three dimensional obturation has contributed to the success of the cases.

\section{References}

1. Treatment of a Non Vital Immature Incisor With Mineral Trioxide Aggregate(MTA). Dental Traumatology. $2003: 19 ; 165-169$

2. RAS Fidel, RG de Carvalho, CH Varela, A Letra, SR Fidel.Complicated Crown Fracture : A Case Report. Braz Dent J , 2006 ;17(1); 83-86

3. Hacmeister DR, Schindler WG, Walker WA $3^{\text {rd }}$, Thomas DD. The sealing ability and retention characteristics of mineral trioxide aggregate in a model of apexification. JOE; 2002; 28; 386390.
4. Bernabe PFE, Holland R, Morandi R, Souza V, Nery MJ, Otoboni Filho JA, Dezan Junior E, Gomes Filho JE. Comparative study of MTA and other materials in retrofilling of pulpless dogs' teeth. Braz Dent J 2005; 16; 149-155.

5. Ghose LJ, Bhagdady VS, Hikmat BYM. Apexification of immature apices of pulpless permanent anterior teeth with calcium hydroxide. J Endod; 1987; 13; 285-290

6. M Torabinejad and Noah Chivian. Clinical applications of Mineral Trioxide Aggregate. JOE;25(3) :march 1999

7. Hayashi M, Shimizu A, Ebisu S. MTA for obturation of mandibular central incisor with open apices: case report.J Endod 2004; $30: 120-122$

8. Torabinejad M, Watson PF, Pitt Ford TR. Sealing ability of a mineral trioxide when used as a root end filling material. J Endod ; 1993; 19; 591-595

9. RL Martin, F Monticelli, WW Brackett, RJ Loushine, Roy A Rockman , M Ferrari, DH Pashley and FR Tray. Sealing properties of mineral trioxide aggregate orthograde apical plugs and root fillings in an in vitro apexification model. JOE; 33(3) ; march 2007

10. P Ghaziani, N Aghasizadeh and M SheikhNezami.Endodontic treatment with MTA apical plugs: a case Report journal of oral science : 2007:49(4) :325-329

11. B. P. Mathews and Mithra Hegde : Management of non vital immature teeth - case reports and reviews Endodontology 2006 ; Issue 1; 18 21 